\title{
Motivation: Outstanding Way to Promote Productivity in Employees
}

\author{
Almas Sabir \\ Department of Management, College of Business Administration, University of Hail, Hail, Kingdom of Saudi Arabia \\ Email address: \\ almas.sabir083@gmail.com \\ To cite this article: \\ Almas Sabir. Motivation: Outstanding Way to Promote Productivity in Employees. American Journal of Management Science and \\ Engineering. Vol. 2, No. 3, 2017, pp. 35-40. doi: 10.11648/j.ajmse.20170203.11
}

Received: May 24, 2017; Accepted: June 12, 2017; Published: July 17, 2017

\begin{abstract}
Employees are the most valuable and unique assets of organization. People often confuse the idea of 'happy' employees with 'motivated' employees. This paper would highlight the different ways to motivate employees and how it helps in promoting productivity of the organization. In this study a detailed discussion would also be there to explain how to make feel that the work they do has meaning. There are many ways to motivate employees. Managers who want to encourage productivity should work to ensure that employees was greatly appreciated and rewarded with diligent employee performance. In order to study the various issues highlighted in this paper related to employee motivation, a large body of literature mainly from different journals have been incorporated. To make the study more relevant only those studies were included which were published in the last few decades. In past research papers few dimensions of motivation were used to explain the different models of motivation theory which has direct influence on employee motivation. The novelty of this study lies in its theoretical framework where authors have made an attempt to come up with a construct having dimensions that directly or indirectly influences employee motivation.
\end{abstract}

Keywords: Motivation, Productivity, Behavior, Capital, Efficiency, Dimensions

\section{Introduction}

Motivation in general referred as the reasons for acting or behaving in a particular way. It gives the reason for people's actions, desires, and needs. Motivation can also be defined as one's direction to behavior or what causes a person to want to repeat a behavior and vice versa. A motive is what prompts the person to act in a certain way, or at least develop an inclination for specific behavior. According to Maehr and Meyer, "Motivation is a word that is parts of the popular culture as few other psychological concepts. Managing motivation is therefore a critical element of success in any business; with an increase in productivity, an organization can achieve higher levels of output.

Research has shown that motivated employees will have following objectives:

(1) A "better" way to complete a task

(2) Be more quality-oriented

(3) Work with higher productivity and efficiency

Gary Vaynerchuk CEO of VaynerMedia said short-term rewards won't keep your office excited. It's all about long- term leadership. According to him 2 things every manager must do to motivate employees.

(1) Lead by example

(2) Know what your employees want

Llopis (2012) draws attention to the increasing relevance of the work-life balance problem for modern employees and stresses its negative impact on the level of employee motivation. Specifically, Llopis (2012) reasons that unless employees achieve an adequate level of work-life balance in personal level, management investment on the level of employee motivation can be wasted.

This viewpoint is based on Hierarchy of Needs theoretical framework proposed by Abraham Maslow (1943), according to which there is a certain hierarchy for individual needs, and more basic human needs need to be satisfied in order for the next level needs to serve as motivators.

In summary, motivated employees will retain a high level of innovation while producing higher-quality work more efficiently. There is no downside-i.e., the opportunity cost of motivating employees is essentially zero, assuming it does not require additional capital to coach managers to act as effective motivators. 


\section{Literature Review}

Motivating employees is vital to any business. Rich Henson has said in his studies that motivating employees is a lot like bathing. The results are not permanent, but it's something you should be doing on a regular basis. Every employee can use a shot of motivation from time to time, no matter how much of a self-starter the person is. It's easy to tell when people are properly motivated because they:

(1) Look for better ways to do a job

(2) Care about customers

(3) Take pride in the work, and

(4) Are more productive.

Leaders motivate people to follow a participative design of work in which they are responsible and get it together, which make them responsible for their performance. Aguinis et al. (2013) stated that monetary rewards can be a very powerful determinant of employee motivation and achievement which, in turn, can advance to important returns in terms of firmlevel performance.

Vuori and Okkonen (2012) stated that motivation helps to share knowledge through an intra-organizational social media platform which can help the organization to reach its goals and objectives. Den andVerburg (2004) found the impact of high performing work systems, also called human resource practices, on perceptual measures of firm performance. Ashmos andDuchon (2000) recognizes that employees have both a mind and a spirit and seek to find meaning and purpose in their work, and an aspiration to be part of a community, hence making their jobs worthwhile and motivating them to do at a high level with a view to personal and social development

A motivated workforce means a highly productive staff, all of which will help to achieve business goals. And this should be a main objective in organizational and business plan. Few points are mentioned with relevant significance of motivating employees-

(1) Completing task in allotted time to increase productivity- When workers are continuously motivated from outside or within, they tend to show passion in their work and perform better. Companies that provide a reason behind challenging jobs are, in turn, motivating them to work hard and reach the goal or accomplish the challenges so provided. As such, when they are faced with productivity goals, they give in their best efforts to reach the challenges and complete their tasks within the allotted time, without any external motivational tools like bonuses and awards. This, in turn, is beneficial for the company through increased production and productivity.

(2) Improved Employee Morale- Motivating employees on a continuous basis can induce them to work hard and accomplish the challenges, thereby improving the morale levels amongst them. A team with high employee morale is in a better position of attending office every day and facing challenges of the job. The happier the workers are, the more productive they turn out to be. Additionally, the company experiences less conflicts and lower incidents of absenteeism.

(3) More Loyal Workforce- The more employees are motivated, the more loyal they are towards their work and the organization, on the whole. It proves to be expensive for the organization to hire new employees by investing time and money on their recruitment. Plus, they come with a high employee turnover (the cost of replacing an employee with another one) to the company. On the other hand, loyal workers lead to saving money in recruitment costs, training, and lost productivity, thereby reducing the employee turnover to a great extent. Besides, a company with a group of motivated and loyal workers is more likely to gain a good reputation amongst potential workers and clients.

(4) Better Creativity- A motivated workforce tends to work freely and more passionately on the tasks assigned. As such, these employees display improved and better levels of creativity and imagination on the job. As a result, a group of innovative and inspired employees help in taking the business to step forward with creative ideas flowing all the while for the betterment of the organization. For inducing more creativity amongst employees, the supervisors have to design such a leadership style which constantly encourages them to provide suggestions, new product ideas, and new cost effective ways of delivering better performances.

(5) Appraisal Opportunities- The more motivated employees are towards their job goals and objectives, the better are their chances of getting promoted. Depending upon the interest and hard work that an employee delivers on the job, he is likely to be rewarded accordingly. As such, better levels of performance are more likely to get an employee recognized amongst other workforce, thereby being benefited with an appraisal, promotion, or increased salary pay.

With the above stated reasons indicating the significance of employee motivation, it is essential to keep the workforce stimulated and encouraged.

According to Lockley (2012) offering training and development programs that effectively contributes to personal and professional growth of individuals is another effective employee motivation strategy. At the same time, Lockley (2012) warns that in order for motivational aspects of training and development initiatives to be increased, ideally they need to be devised and implemented by a third party with relevant competency and experience.

Alternative working patterns such as job-rotating, jobsharing, and flexible working have been branded as effective motivational tools by Llopis (2012). Moreover, Llopis (2012) argues that motivational aspects of alternative working patterns along with its other benefits are being appreciated by increasing numbers of organisations, however, at the same time; many organisations are left behind from benefiting from such opportunities. 
An interesting viewpoint regarding the issue has been proposed by Wylie (2004), according to which members of management primarily should be able to maintain the level of their own motivation at high levels in order to engage in effective motivation of their subordinates. Accordingly, Wylie (2004) recommends managers to adopt a proactive approach in terms of engaging in self-motivation practices.

Furthermore, Wylie (2004) recommends concentrating on specific variations of intangible motivational tools such as celebrations of birthdays and other important dates with the participation of whole team

According to Thomas (2009) the main challenge of motivation in workplaces is identifying what motivates each individual employee taking into account his or her individual differences. In other words, individual differences have been specified by Thomas (2009) as the major obstruction for management in engaging in employee motivation in an effective manner.

\section{Research Methodology}

The main objective to write this review is to highlight the flow of motivation and to reveal what motivation techniques work more efficiently in different stages of life. This study provides useful managerial implication for employee motivation in an organization. Business owners often fret about the best way to increase employee motivation. Some might wonder, however, why simply providing a paycheck is not enough. Looking closely at what causes a loss of motivation, and recognition of the business' dependence on employees, reveals it is fundamental for employees to bring their enthusiasm to the workplace to increase the company's bottom line.

(1) A motivated workforce will work in a way that provides the greatest value it can to the organization. The success of the company will suffer as a result of employees working below their level of capability.

(2) Employee imagination and creativity can feed into the innovations made by a new business.

(3) A company with an environment that prevents demotivation, or includes the financial compensation and recognition of a formalized motivation program, will retain good workers.

(4) A company can achieve its full potential only by making use of all the financial, physical, and human resources that it has. It is through these resources that the employees get motivated to accomplish their duties. This way, the enterprise begins to glisten as everyone is doing their best to fulfill their tasks.

(5) Any enterprise has its goals, which can be achieved only when there is a proper resource management, the work environment is a cooperative, one and all employees are directed by their objectives.

(6) Needs, wishes and desires are interrelated, representing the thrust to act. These wants should be understood by the manager and he/she should formulate and frequently update comprehensive motivation strategies.

(7) Managers should seek to empower them through promotion opportunities, monetary and non-monetary rewards, or disincentives in case of inefficient employees.

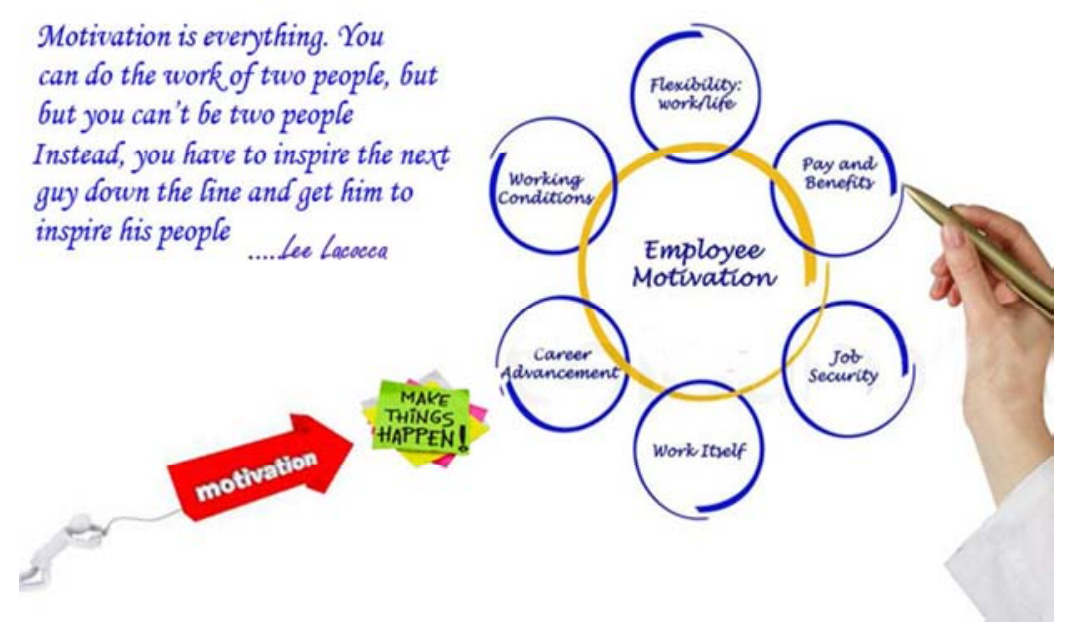

Figure 1. Motivation: Makes things happen.

Realistically speaking, the duties at work can be most of the time tedious, repetitive and quite boring. Most of us don't go to work excited that we're going to have another day in which we'll respond to dozens of emails, complete a pile of Excel spreadsheets, or other tasks which fall into the dullness category.

With that in mind, managers need to find creative ways in which to consistently keep their employees motivated as much as possible. Motivation is highly important for every company due to the benefits that it's able to bring.

\section{Discussion}

Measuring employee motivation is often a challenging prospect as motivation is a qualitative, rather than quantitative, value. In other words, it cannot be easily 
measured with numbers or statistics. Unless your business is the type that uses targets and sales incentives, you can often estimate the motivation of your employee with the use of surveys and questionnaires, directed to the employee and the customer.

(1) While employee productivity is not necessarily the same as employee motivation, it can give you a good estimate of the amount of effort your employee is putting into the business.

(2) Conduct a survey of your employees. Specifically, ask them how much they care about the business' success. According to Personnel Today, an employee who cares more about the success of the business is more likely to be more motivated in his or her daily tasks. Use a third-party service for this kind of survey, as employees may not give you a completely honest answer if you ask them yourself.

(3) A highly motivated employee will likely result in more satisfied customers than that of an employee with less motivation. Conduct the survey either yourself or with the use of a specialized survey company, but ask customers about their experiences while they are still fresh. The longer you wait, the less accurate your result.

(4) Determine a job candidate's motivation at the interview stage. Ask about a previous project the candidate was engaged in, focusing on specific steps he took to complete the project, improvements he made along the way, and the level of satisfaction he had with the work. By doing this, you can assess an individual's motivation level in performing a specific type of work.

(5) Provide a questionnaire asking employees whether they feel their training and overall level of preparation for their jobs have been adequate. Many employees will not volunteer this information on their own because they believe a lack of training places their job at risk

(6) Examine your own expectations for your people. It's a studied and measured fact that people tend to perform up -- or down -- to their expected performance levels. This phenomenon is known as the Pygmalion Effect. Ask yourself if, as a manager, you aren't inadvertently causing some people to feel less motivated by giving them soft tasks or failing to solicit their feedback on important matters.

(7) Ask employees during their review sessions what their five-year career plans are. This can help you gauge a particular employee's level of motivation. For example, if an employee states she's comfortable where she is, this indicates low motivation to advance her career. Conversely, if that same person says she wants your job, take that as a positive in terms of engagement.

(8) Observe how often employees come to you with questions about their roles and tasks. Proactive engagement shows initiative and a desire to please.
(9) Another way of finding out if employees are satisfied at work is by conducting a one-on-one review with them as management need to focus on individuals and their specific needs.

(10)Create a platform to allow you and your team voices to amplify.

Allow team to speak up to express an opinion. In today's workplace where 'Yes-men' (and women) are all too plentiful, people who are willing to stick their neck out and question the status quo thinking not only add more value, but become more valuable for everyone.

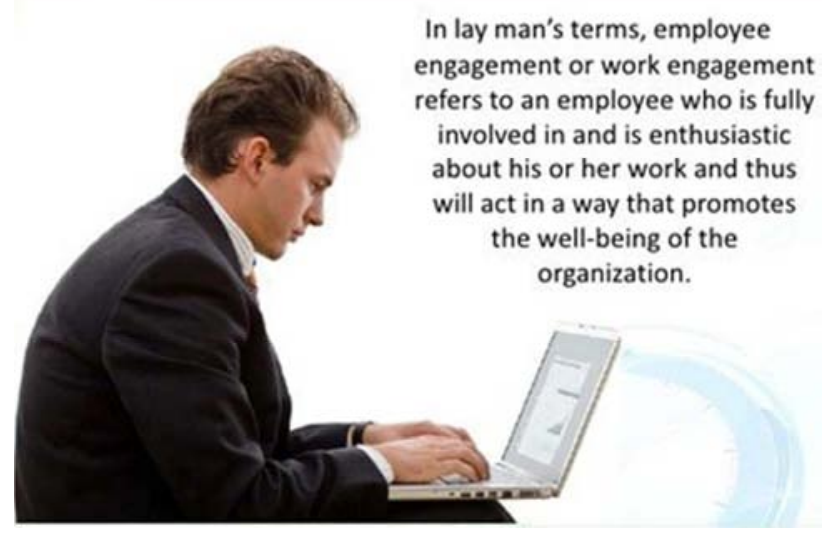

Figure 2. Employee Engagement.

Employee motivation has a large internal component. Some people are simply driven more than others to succeed, advance and contribute. However, many employees use external factors such as pay, position and involvement as gauges for how motivated they should feel. As a manager, it's difficult to be all things to all team members. However, these are the certain methods we can use to gauge motivation and make changes accordingly.

\section{Recommendation}

One of the most important factors in employee motivation is how often their hard work is recognized.

(1) If an employee continues to expend discretionary effort to produce exceptional results, and that effort isn't recognized, don't expect it to keep happening.

(2) It's not just important to recognize great work -- how you go about recognizing your team's contributions has a significant impact. An annual bonus at the end of the year isn't likely to do the trick.

(3) Your organization needs to have an employee recognition program. You can let the productive and efficient employees choose their reward from a list of options. This will make them feel valued and more loyal towards the organization.

(4) The line managers and the supervisors can ensure efficient communication with their team through a direct medium instead of relying on mails all the time. Direct feedback and praise ensure a high comfort level with direct managers, fostering trust and translating 
into high motivation and increased productivity.

(5) A flexible work schedule offers relief to the employee force, and ensures them that the organization values their efforts. Flexible timing, telecommuting and job sharing, will enable employees to finish their work while maintaining a good work life balance. This will motivate the employees, and help you retain some of the best talent in the industry.

(6) Some employees find additional responsibilities a highly motivating element in their job. It lets them enjoy greater ownership in different organizational efforts, and thus, makes them more motivated to strive for business success.

(7) It's important to build a solid foundation for your employees so they feel invested in the company.

(8) Tell them about the history of the business and your vision for the future. Ask them about their expectations and career goals, as well as how you can help them feel like part of the team. When any new employee starts, make sure they receive a thorough welcome orientation.

(9) Most employees are looking for advancement opportunities within their own company. Work with each of them to develop a career growth plan that takes into consideration both their current skills and their future goals. If employees become excited about what's down the road, they will become more engaged in their present work.

(10)Once in a while, you have put work aside and do something nice for the people who work for you.

(11)Treat the office to a pizza lunch or take everyone to the movies. Reward employees with an unexpected day off or by closing the office early on a random Friday afternoon. These little diversions can go a long way toward improving productivity.

\section{Conclusion}

Creating a workplace with excellent morale and motivated employees is a long-term project, and needs to be embedded within the fabric of an organization's daily operations. Highly motivated and engaged personnel are a tremendous asset to any organization. While money is an important foundational consideration, the main factors that attract and maintain "talent" within an organization include:

(1) Recognition

(2) Having Interesting Work To Do

(3) Being Heard By Management

(4) Having Skilled Managers

(5) Having Good Communication Flows

(6) Being Provided With Opportunities for Advancement.

Managers recognize that motivation is personal to the individual. If employees feel that they are being treated fairly, they will be more likely to give their best. Motivation comes from within an individual. Enterprise managers therefore need to find out about the personal goals and aspirations of their employees. What motivates one employee will not necessarily motivate another.

In addition to ensuring fair pay and conditions, it is also essential for the business to meet the higher order needs of individual employees. These include the need for recognition and fulfillment at work.

\section{References}

[1] https://en.wikipedia.org/wiki/Motivation.

[2] The Importance of Motivation.

[3] https://www.boundless.com/management/textbooks/boundless -management-textbook.

[4] https://www.google.com.sa/search?site $=\&$ source $=h p \& q=i m p o$ rtance + of + motivating + employee.

[5] Importance Of Employee Motivation, speedupcareer.com.

[6] Why Do Organizations Need to Motivate Their Employees? By Catherine Lovering.

[7] Why is Employee Motivation So Important for Performance? Posted By Jason Silberman On May 9, 2013 Posted In Employee Performance.

[8] How to Measure the Motivation of Your Employee by James Green.

[9] http://smallbusiness.chron.com/measure-motivationemployee.

[10] How to Measure Motivation in a Workplace by David Lipscomb, $\quad \mathrm{http} / /$ work.chron.com/measure-motivationworkplac.

[11] 20 Simple Ways to Increase Motivation in the Workplace By George Dickson on January 13, 2016.

[12] http://www.actioncoach.com/blog/2015/05/05/increasemotivation-workplace.

[13] Ten Tips on Improving Employee Motivation By All Business Editors | In: Staffing \& HR.

[14] http://www.bpir.com/employee-motivation-bpir.com/menu-id$71 /$ conclusion.html $\mathrm{http} / /$ businesscasestudies.co.uk/enterprise-rent-acar/motivation-in-action/conclusion.html

[15] Motivating employees: What every manager needs to know, November 19, 2012 By Rich Henson.

[16] 2 Things Every Manager Must Do to Motivate Employees, By Gary Vaynerchuk CEO of VaynerMedia.

[17] https://www.researchgate.net/publication/263225315_A_litera ture review on motivation Bruce, A. Pepitone, J. S. (1999) "Motivating Employees" McGraw-Hill International.

[18] Kreitner, R. \& Cassidy, C. (2012) "Management" Cengage Learning.

[19] Llopis, G. (2012) "The Top 9 Things That Ultimately Motivate Employees to Achieve" Forbes, April 6, 2012.

[20] Lockley, M. (2012) “The Secret to Motivating a Team” The Guardian, January 6, 2012. 
[21] Maslow, A. H. (1943) "The Theory of Human Motivation" Psychological Review, 50(4)6.

[22] Shields, J. (2007) "Managing Employee Performance and Reward: Concepts, Practices, Strategies" Oxford University Press.
[23] Thomas, K. T. (2009) "Intrinsic Motivation at Work: What Really Drives Employee Engagement" 2nd edition, BerrettKoehler Store.

[24] Wylie, K. (2004) "Managers Get the Staff They Deserve" GRIN Verlag. 